This item was submitted to Loughborough's Research Repository by the author.

Items in Figshare are protected by copyright, with all rights reserved, unless otherwise indicated.

\title{
Development of a scale to measure gamer experiences in sport video games
}

PLEASE CITE THE PUBLISHED VERSION

https://doi.org/10.1504/IJSMM.2018.10014488

PUBLISHER

Inderscience

VERSION

AM (Accepted Manuscript)

\section{PUBLISHER STATEMENT}

This work is made available according to the conditions of the Creative Commons Attribution-NonCommercialNoDerivatives 4.0 International (CC BY-NC-ND 4.0) licence. Full details of this licence are available at: https://creativecommons.org/licenses/by-nc-nd/4.0/

\section{LICENCE}

CC BY-NC-ND 4.0

\section{REPOSITORY RECORD}

Leng, Ho Keat, and Do Young Pyun. 2019. "Development of a Scale to Measure Gamer Experiences in Sport Video Games”. figshare. https://hdl.handle.net/2134/25389. 
Development of a Scale to Measure Gamer Experiences in

Sport Video Games 


\begin{abstract}
The aim of this study is to develop a scale to measure gamer experiences in sport video games. A two-phase data analysis was conducted with 400 respondents randomly assigned to one of two phases. In each phase, respondents were tasked to play a sports car racing game and complete a survey instrument. The study identified six dimensions of sports video games based on gamer experience. These are Challenge, Competence, Flow, Immersion, Enjoyment and Negative Affect. Using this scale, it will be possible to examine differences in gamer experience across sports video games. More importantly, it will be possible to examine the relationship between gamer experience and sponsorship effectiveness in future studies using this scale.
\end{abstract}

Keywords: sport video games, game experience, scale development, reliability, validity 


\section{Development of a Scale to Measure Gamer Experiences in Sport Video Games}

The computer and video game business is a major industry. Entertainment Software Association, an association representing the computer and video games industry in the United States, estimated that the total consumer spending in the United States was more than US\$22 billion in 2014. Video games alone accounted for US $\$ 5$ billion in sales. In particular, the association also found that sport and racing games are popular with gamers, with $18.5 \%$ of video games sold in 2014 from these genres. These include top selling games like Madden NFL15, NBA 2K15 and FIFA15 (Entertainment Software Association, 2015).

The popularity of sports and racing games has spawned interest from marketers in commercial organisations (Cianfrone, Trail, Zhang, \& Lutz, 2008; Clavio, Kraft, \& Pedersen, 2009). Given that the majority of gamers are males between the ages of 18 to 35, industries targeting this demographic segment are particularly keen to tap on this medium to reach their target customers (Kim, Walsh, \& Ross, 2008; Stein, Consalvo, \& Mitgutsch, 2012). Research from the industry has also suggested that video games are becoming more popular and mainstream (Chaney, Lin, \& Chaney, 2004). In 2014, it was found that gamers are getting older, averaging 35 years of age. In addition, $44 \%$ of gamers are of female gender (Entertainment Software Association, 2015). This development has only expanded the number of industries and companies interested in sports video games as a marketing communications platform.

Consequently, many research studies were conducted to examine the effectiveness of in-game advertisements. In particular, studies have focused on whether gamers are able to recall and recognize the brands that appeared in the game. In general, it was found that the recall rate of in-game advertisements was low (Lee \& Faber, 2007; Leng, 2011; Schneider \& Cornwell, 2005; Walsh, Kim, \& Ross, 2008). However, this recall rate can be increased by making the brand more prominent within the game (Chaney et al., 2004; Leng, Quah, \& Zainuddin, 2010; Schneider \& Cornwell, 2005). As such, many studies have focused on how brands can be made more prominent within games.

More recently, it was found that gamer experiences had an effect on brand recall rate (Herrewijn \& Poels, 2013). However, the number of studies in this area remains small particularly for the genre of sports video game. This is possibly due to the absence of a scale to measure gamer experience in a sports video game.

The measures for gamer experience were orignially developed as a means to aid game designers in evaluating computer games in general (Cowley, Charles, Black, \& Hickey, 2008; Sweetser \& Wyeth, 2005). As such, it is not known whether these measures developed for games in general can be applied to the specific genre of sport video games. The aim of this research is to develop a scale to measure gamers' experience of sport video games based on earlier measures of gamers' experience. This will allow future research to be conducted to examine the relationship between gamers' experience and the effectiveness of marketing strategies using sport video games. In particular, the development of the scale will allow future research to examine the relationship between gamers' experience and the effectiveness of in-game advertisements.

\section{Literature Review}

Games come in a variety of genres. Within each genre, games can vary widely. As such, there have been several attempts to create a scale to measure gamer experiences as a basis for comparison across games (Barbara, 2014). These attempts have generally focused on the idea that enjoyable gaming experience depended on whether the game allowed the gamer to be immersed or engaged with the game (Brockmyer et al., 2009; Cowley et al., 
2008; Sweetser \& Wyeth, 2005). Hence, the concepts of immersion, presence and flow are widely discussed in such studies (Borderie \& Michinov, 2016; Hrabec \& Chrz, 2015).

One of the earlier models based on these concepts was the Gameflow model (Sweetser \& Wyeth, 2005). This model was developed to aid game evaluation and design by studying real-time strategy games. It included eight core elements of concentration, challenge, skills, control, clear goals, feedback, immersion and social interaction. It was believed that games must capture the concentration of the gamer through sufficiently high cognitive work load but yet is at an appropriate level of challenge based on the gamers' skill level. The game should have clear goals and a feedback mechanism so that the gamer can achieve a sense of control. When these elements are in place, the gamer should feel a sense of immersion in the game (Sweetser \& Wyeth, 2005).

It was also clear from the model that gaming experience is more than just engagement with a game. The last component of the Gameflow model was social interaction, which is not part of flow theory. However, as the literature had shown the centrality of social interaction in studying gamer experience, it was retained as part of the model (Sweetser \& Wyeth, 2005; Sweetser, Johnson, \& Wyeth, 2012).

Subsequently, later models extended from this by incorporating more facets of game experience. Poels, deKort \& Ijsselsteijn (2007) initially suggested that gaming experiences include facets of enjoyment, flow, imaginative immersion, sensory immersion, suspense, competence, negative affect, control and social presence. This was later developed into the Game Experience Questionnaire. In this iteration, it comprise Challenge which measures the stimulation players perceive and the amount of effort they have to put into the game; Competence which refers to how successful and skillful people feel while playing a game; Tension which measures the degree to which players feel frustrated and annoyed; Flow which indicates the experience of being absorbed into the game world; Immersion which measures the experience of being surrounded by the game as a result from the interest in and appeal of the sensory and imaginative qualities of the game; Positive Affect which measures players' fun and enjoyment of the game; and Negative Affect which measures the degree to which players are feeling bored and distracted (Herrewijn \& Poels, 2013).

However, models that are developed based on a specific genre of game may not be suited to explain the experiences of gamers in a different genre of games (Sweetser \& Wyeth, 2005). Subsequently, there have been attempts to validate or adapt scales developed in other genres of games to be used in specific genres. For example, an earlier study was conducted to adapt the Game Experience Questionnaire which was originally developed for digital games to be used in board games (Barbara, 2014).

Specific to sport video games, it can be argued that sport video games are also different from other game genres. Playing sport video games is a form of hedonic consumption behavior (Kim \& Ross, 2006; Kwak, Clavio, Eagleman, \& Kim, 2010). The realistic and interactive features of sport video games allow gamers to be immersed in the game and fulfill sporting fantasies (Kwak et al., 2010; Lee, Seo, \& Green, 2013). Hence, gamers are more likely to feel positive emotions when playing sport video games.

More importantly, brand placements in sport video games, including car racing games, are viewed differently from other game genres. Brands are commonly found in sports events and venues (Kim \& McClung, 2010; Nelson, Keum, \& Yaros, 2004). As such, ingame advertisements in sport video games are acceptable as they add realism to the game. For example, gamers expect to see soccer players from Manchester United sporting shirts with "Vodafone" logos and drivers in a car racing games driving well-known brands of cars (Nichols, Farrand, Rowley, \& Avery, 2006). Such in-game advertisements can affect gamer experience positively. 
Related to this, it has been suggested that gamers' experience of the game can also affect the recall rate of in-game advertisements. In a recent study, Herrewijn \& Poels (2013) manipulated the difficulty of a game to create differences in gaming experience. Easier games led to more positive emotional experiences, fewer negative experiences and less arousal. In turn, this affected the processing and evaluation of in-game advertisements (Herrewijn \& Poels, 2013).

This concurred with earlier studies which have approached the recall of in-game advertisements from the perspective of the individual gamer and the ability of the gamer to devote cognitive resources to attend to advertisement cues within the game (Lee \& Faber, 2007). Individuals need to expend cognitive resources in receiving stimuli, creating a mental picture of these stimuli and reproducing these mental images. According to the Limited Capacity Model of Mediated Message Processing, individuals have a limited capacity in processing such cognitive information (Lang, 2000). The theory suggests that with limited capacity, gamers will need to allocate cognitive resources between playing a game and processing other peripheral information. Gamers who are more proficient will be able to devote less cognitive effort in playing the game and as such, they are more likely to be able to utilize cognitive resources to attend to peripheral cues. Hence, proficient gamers are more likely to recall a larger number of in-game advertisements.

In summary, the above discussion has suggested that while there are several scales developed to measure gamer experience, they have not been developed to be used in the specific genre of sports video games. Noting that the genre of sport video game can be different from other games, it will be necessary to develop a scale to measure gamer experience in sport video games. More importantly, noting recent studies establishing a relationship between gamers' experience and effectiveness of marketing strategies using ingame advertisements, the development of this scale will be useful to extend studies in this area. The aim of this study is thus to adapt from existing scales to develop a scale that can measure gamers' experience in sport video games.

\section{Method}

\section{Research Subject and Data Collection}

In this study, a total of 400 respondents from a tertiary educational institution were employed after removing 10 inattentive or uncooperative cases. The mean age of the respondents was 22.20 years with 168 of the respondents (42\%) of female gender. Respondents were required to play a sports car racing game, F1 2014 on the Sony Playstation 3. All respondents were required to select the same car and driver to minimize differences in extraneous factors. This was followed by the completion of an online survey instrument on the experience of the gameplay. This method of collecting data on gamer experience is commonly used (Borderie \& Michinov, 2016). The duration of gameplay and completion of survey took no more than 30 minutes for each respondent. In return, respondents are provided with $\mathrm{S} \$ 5$ in vouchers as a token of appreciation for their time.

\section{Instrument Development}

Poels et al. (2007) defined and conceptualised the theoretical framework of the game experience in the digital games context and proposed nine dimensions (Enjoyment, Flow, Imaginative Immersion, Sensory Immersion, Suspense, Competence, Negative Affect, Control and Social Presence). Extending this concept, Ijsselsteijin, de Kort, and Peols (2013) developed the Game Experience Questionnaire more comprehensively by providing three modular structures: the core questionnaire, the social presence module, and the post-game module. The first two scales were designed to assess "the player's feelings and thoughts", 
while the last module assessed "how the players felt after they had stopped playing" (Ijsselsteijin et al., 2013, p. 3). While the core questionnaire measured players' psychological experiences in reaction to the content of the game, the social presence module assessed the player's psychological and behavioural involvement with other social entities (Ijsselsteijin et al., 2013). Particularly, the player in-game experience included the seven dimensions of Immersion, Flow, Competence, Positive Affect, Negative Affect, Tension, and Challenge. This differed from Poels et al. (2007) in several ways. Firstly, enjoyment, control, and social presence were not considered. Secondly, imaginative and sensory immersion were merged into immersion. Finally, suspense was split into tension and challenge. Using the in-game experience subscale, Herrewijin and Poels (2013) investigated the impact of player experiences with in-game advertising. The measurement model test revealed that the factors were generally deemed psychometrically sound.

Adapting from the Game Experience Questionnaire and other studies (Herrewijn \& Poels, 2013; Ijsselsteijin et al., 2013; Poels et al., 2007), the researchers obtained a set of items for the domains. The evaluation of content validity was performed by the relevance of items to their respective factors with information obtained from a panel of experts in the field. A total 24 items corresponding to six factors of Challenge, Competence, Flow, Immersion, Enjoyment and Negative Affect were finalised and prepared particularly for the racing game experience. Challenge measured the stimulation players perceive (e.g., I felt challenged in playing the game); Competence referred to how successful the respondent was in playing the game (e.g., At the end of the game, I felt a sense of accomplishment); Flow measured the level of absorption in the game (e.g., I lost track of time playing this game); Immersion indicated the extent of being surrounded by the interest in and appeal of the sensory and imaginative qualities of the game (e.g., The game feels so real); Enjoyment measured the respondents' level of enjoyment of the game (e.g., Playing the game was a pleasurable experience); and Negative Affect measured the degree to which players experienced negative feelings of boredom and frustration (e.g., The game was a disappointment).

\section{Data Analysis}

A two-phase data analysis was conducted to develop a reliable and valid scale of digital game experience. Respondents were randomly assigned to one of two phases. In phase one, the first data set $(n=169)$ was analyzed using IBM SPSS 21.0. Descriptive statistics, internal consistency reliability, and exploratory factor analysis (EFA) were utilized to purify the proposed scale. As the six factors in the proposed model were assumed to be correlated (Brockmyer et al., 2009; Chen et al., 2012), a principle component with an oblique rotation was implemented to uncover the underlying structures of the variables on the factor pattern matrix.

In phase two, a confirmatory factor analysis using the second data set $(n=231)$ was performed to confirm overall goodness-of-fit, reliability, and validity of the measures which were retained from the phase one. The current sample size met the widely accepted rule of thumb of 10 subjects per indicator for CFA (Hair et al., 1998). For the goodness-of-fit of the measurement model, $\chi^{2} / d f$ ratio, root mean squared error of approximation (RMSEA), incremental fit index (IFI), and comparative fit index (CFI) were examined. Composite reliability and average variance extracted (AVE) were calculated as reliability test. For validity of the scale, convergent and discriminant validity tests were carried out. Convergent validity was assessed by the indicators' factor loadings, and discriminant validity was examined by looking at AVEs and correlations among the factors. In order to satisfy discriminant validity a factor, AVE of the factor should exceed the squares of its correlations with the other factors (Fornell \& Larcker, 1981). All analyses employed in the phase two were performed using LISREL 8.80. 


\section{Results and Discussion}

\section{Phase One: Data Purifications}

No invalid values or outliers in the first set were identified. The univariate normality assumption was tested using skewness and kurtosis statistics. Table 1 shows skewness $(-0.99$ $\sim 1.07)$ and kurtosis $(-0.99 \sim 1.35)$ values of the 24 experience items were all within \pm 2.00 , meeting the criteria suggested by Tabachnick and Fidell (2013). For internal consistency among the respective items, Cronbach's alpha and item-to-total correlation were calculated and utilized to remove the poor performing items (see Table 1). Cronbach's alphas of the six factors ranged from .76 to .94, meeting the .70 cut-off (Nunnally \& Bernstein, 1994). Out of 24 items, however, three items showed their item-to-total correlations (.44 for Challenge4, .48 for Flow1, and .42 for Immersion4) lower than the accepted level of .50 (Bearden, Netemeyer, \& Teel, 1989), thus were removed from the item pool.

On closer analysis, it was deemed appropriate to remove the items as they were conceptually different from the rest of the items. For example, Challenge4 (I was mentally exhausted after playing the game) was slightly different from the other statements on the testing or challenging of abilities.

Accordingly, the retained 21 items retained were carried out to conduct EFA. A principal component analysis with oblique rotation was implemented to identify the facture structure of the items. Based on Kaiser's rule, six factors with eigenvalues larger than one were retain, which accounted for $74.51 \%$ of the total variance. The resulting pattern matrix is shown in Table 2. Items having a factor loading less than .40 were not considered to be acceptable (Hair, Anderson, Tatham, \& Black, 1998). According to the pattern matrix, all items properly loaded on their proposed factors. 
Table 1

Descriptive Statistics in the First Date Set $(n=169)$ and the Second Data Set $(n=231)$

\begin{tabular}{|c|c|c|c|c|c|c|}
\hline Factor & Item & Mean & SD & Skewness & Kurtosis & $\alpha$ \\
\hline \multirow{4}{*}{ Challenge } & I felt challenged in playing the game. & 3.84(3.77) & $1.00(1.01)$ & $-0.70(-0.59)$ & $-0.05(-0.29)$ & \multirow{4}{*}{$\begin{array}{c}.76 \\
(.79)\end{array}$} \\
\hline & This game requires me to perform to the best of my ability. & $3.80(3.59)$ & $0.98(0.99)$ & $-0.68(-0.44)$ & $0.02(-0.32)$ & \\
\hline & Playing this game taxes the limits of my abilities. & $3.17(3.25)$ & $1.12(1.00)$ & $0.01(-0.21)$ & $-0.77(-0.44)$ & \\
\hline & I was mentally exhausted after playing the game. & $2.56(\mathrm{~N} / \mathrm{A})$ & $1.24(\mathrm{~N} / \mathrm{A})$ & $0.46(\mathrm{~N} / \mathrm{A})$ & $-0.77(\mathrm{~N} / \mathrm{A})$ & \\
\hline \multirow{4}{*}{ Competence } & I am skillful in this game. & $2.17(2.10)$ & $1.09(1.08)$ & $0.74(0.70)$ & $-0.14(-0.40)$ & \multirow{4}{*}{$\begin{array}{c}.79 \\
(.86)\end{array}$} \\
\hline & I am a success at the game. & $2.17(2.10)$ & $1.05(1.04)$ & $0.77(0.57)$ & $0.13(-0.47)$ & \\
\hline & I am proud of my achievements in the game. & $2.30(2.17)$ & $1.19(1.09)$ & $0.71(0.66)$ & $-0.36(-0.31)$ & \\
\hline & At the end of the game, I felt a sense of accomplishment. & $2.43(2.30)$ & $1.16(1.08)$ & $0.45(0.49)$ & $-0.72(-0.55)$ & \\
\hline \multirow{4}{*}{ Flow } & This game requires my full concentration. & $4.04(\mathrm{~N} / \mathrm{A})$ & $0.98(\mathrm{~N} / \mathrm{A})$ & $-0.99(\mathrm{~N} / \mathrm{A})$ & $0.55(\mathrm{~N} / \mathrm{A})$ & \multirow{4}{*}{$\begin{array}{c}.81 \\
(.77)\end{array}$} \\
\hline & I felt completely absorbed in the game. & $3.73(3.74)$ & $1.11(1.00)$ & $-0.68(-0.66)$ & $-0.36(-0.11)$ & \\
\hline & For a while, I forgot everything around me. & $3.31(3.47)$ & $1.22(1.12)$ & $-0.34(-0.24)$ & $-0.90(-0.82)$ & \\
\hline & I lost track of time playing this game. & $3.32(3.37)$ & $1.25(1.17)$ & $-0.35(0.05)$ & $-0.95(-1.18)$ & \\
\hline \multirow{4}{*}{ Immersion } & The game feels so real. & $2.72(2.72)$ & $1.08(1.06)$ & $0.01(0.15)$ & $-0.98(-0.77)$ & \multirow{4}{*}{$\begin{array}{c}.76 \\
(.73)\end{array}$} \\
\hline & I felt like I was a real F1 driver. & $2.46(2.38)$ & $1.11(1.03)$ & $0.30(0.34)$ & $-0.99(-0.73)$ & \\
\hline & When the game ended, I had a sense of returning to the real world. & $3.27(3.16)$ & $1.11(1.03)$ & $-0.37(-0.30)$ & $-0.63(-0.64)$ & \\
\hline & Everyday worries became less important while playing the game. & 3.33(N/A) & $1.26(\mathrm{~N} / \mathrm{A})$ & $-0.34(\mathrm{~N} / \mathrm{A})$ & $-1.03(\mathrm{~N} / \mathrm{A})$ & \\
\hline
\end{tabular}




\begin{tabular}{|c|c|c|c|c|c|c|}
\hline \multirow{4}{*}{ Enjoyment } & The game was fun. & $3.86(3.75)$ & $0.96(0.94)$ & $-0.92(-0.93)$ & $0.53(0.96)$ & \multirow{4}{*}{$\begin{array}{c}.94 \\
(.95)\end{array}$} \\
\hline & I enjoyed the game. & 3.95(3.81) & $0.89(0.91)$ & $-0.93(-0.96)$ & $0.84(1.25)$ & \\
\hline & This is a good game. & $3.76(3.61)$ & $0.97(0.95)$ & $-0.87(-0.86)$ & $0.55(0.77)$ & \\
\hline & Playing the game was a pleasurable experience. & 3.82(3.66) & $0.91(0.94)$ & $-0.99(-0.99)$ & $1.35(1.11)$ & \\
\hline & The game was frustrating. & $2.91(2.90)$ & $1.11(1.13)$ & $-0.23(0.17)$ & $-0.89(-0.96)$ & \\
\hline Negative & I was irritated with many aspects of the game. & $2.52(2.65)$ & $1.08(1.07)$ & $0.47(0.51)$ & $-0.40(-0.45)$ & .81 \\
\hline \multirow[t]{2}{*}{ Affect } & The game was boring. & $2.13(2.23)$ & $1.08(0.98)$ & $1.07(0.73)$ & $1.02(0.23)$ & \multirow[t]{2}{*}{$(.81$} \\
\hline & The game was a disappointment. & $2.04(2.21)$ & $1.03(0.95)$ & $0.84(0.74)$ & $0.54(0.47)$ & \\
\hline
\end{tabular}

Note: The statistics calculated from the second data set are shown in parentheses 
Table 2

EFA Pattern Matrix in the First Data Set $(n=169)$

\begin{tabular}{lrrrrrr}
\hline & 1 & 2 & 3 & 4 & 5 & 6 \\
\hline Challenge1 & -.07 & .21 & -.01 & -.14 & -.82 & .02 \\
Challenge2 & .04 & -.17 & .14 & .04 & -.83 & -.13 \\
Challenge3 & .09 & .11 & -.07 & .23 & -.75 & .09 \\
Competence1 & .13 & -.80 & .13 & .05 & .12 & -.15 \\
Competence2 & .03 & -.85 & .15 & -.05 & .08 & -.02 \\
Competence3 & -.05 & -.58 & -.41 & -.22 & -.06 & .37 \\
Competence4 & -.04 & -.50 & -.28 & -.19 & -.02 & .56 \\
Flow2 & .17 & -.32 &. $\mathbf{4 9}$ & -.01 & -.30 & .07 \\
Flow3 & .02 & -.13 & .78 & -.03 & -.12 & .15 \\
Flow4 & -.07 & -.02 &. .82 & -.16 & -.03 & .09 \\
Immersion1 & .11 & .11 & .30 & -.08 & -.10 &. $\mathbf{6 4}$ \\
Immersion2 & .21 & .08 & .26 & .02 & .09 & .70 \\
Immersion3 & .13 & .09 & .40 & .14 & -.09 &. $\mathbf{4 7}$ \\
Enjoyment1 & .95 & .00 & -.05 & -.01 & .03 & .05 \\
Enjoyment2 & .93 & -.11 & -.03 & .05 & .03 & .01 \\
Enjoyment3 &. $\mathbf{9 0}$ & .03 & -.05 & .00 & -.06 & .03 \\
Enjoyment4 & .85 & -.10 & .01 & -.03 & .02 & .07 \\
Negative1 & .04 & .09 & -.07 &. $\mathbf{8 6}$ & -.02 & .01 \\
Negative2 & -.11 & -.01 & -.04 &. .82 & -.12 & -.03 \\
Negative3 & -.55 & -.10 & -.10 & .39 & .17 & .14 \\
Negative4 & -.50 & -.16 & .01 & .52 & .09 & -.02 \\
\hline
\end{tabular}

\section{Phase Two: Testing the Measurement Model}

Based on the results from the internal consistency tests and the EFA, a six-factor model of digital game experience with 21 items was recommended and utilized for further analysis in the second data collection $(n=231)$. No problematic observations were inspected in the second data set. The normality of the measures was supported as skewness and kurtosis statistics of 21 items ranged within \pm 2.00 : -0.99 to 0.74 for skewness and -1.18 to 1.25 for kurtosis. Using CFA, the goodness-of-fit, reliability and validity of the model were tested. The overall model fit tests showed the adequacy of the model to the data: $\chi^{2}(174)=560.81$, RMSEA = .0988, IFI = .92, and CFI = .92 (Kelloway, 1998; Kline, 1998).

For reliability test, composite reliability and the AVE scores were calculated (see Table 3). The composite reliability of the measures of the six factors ranged from .75 to .95, meeting the .60 cut-off (Bagozzi \& Yi, 1988). In addition, all AVE scores ranged from .51 to .81, exceeding the .50 suggested value (Fornell \& Larcker, 1981).

The tests for validity included convergent validity using factor loadings and discriminant validity assessed by the correlation coefficients among the factors and the AVE scores. Table 3 shows six items' (competence3, competence4, flow2, immersion3, negative1, and negative2) factor loadings ranging from .54 to .67 were less than .707 recommended value, indicating lack of convergent validity that those items had more unique variance than common variance (Fornell \& Larcker, 1981). Discriminant validity of a factor is achieved when AVE value for the factor is greater than the squared correlations between the factor and other factors (Fornell \& Larcker, 1981). The results showed that the squared correlations among the factors were all smaller than AVE scores for six factors. Discriminant validity was achieved as each factor represented more variance in its indicators than it shared with other factors. 
Table 3

Internal Structures in the Measurement Model in the Second Data Set $(n=166)$

\begin{tabular}{|c|c|c|c|c|}
\hline Factor & Indicator & $\begin{array}{l}\text { Factor } \\
\text { loading }\end{array}$ & AVE & $\begin{array}{l}\text { Composite } \\
\text { reliability }\end{array}$ \\
\hline \multirow{3}{*}{ Challenge } & Challenge1 & $.78^{*}$ & \multirow{3}{*}{.55} & \multirow{3}{*}{.79} \\
\hline & Challenge2 & $.72 *$ & & \\
\hline & Challenge3 & $.72 *$ & & \\
\hline \multirow{5}{*}{ Competence } & Competence1 & $.85^{*}$ & \multirow{5}{*}{.60} & \multirow{6}{*}{.85} \\
\hline & Competence2 & $.92 *$ & & \\
\hline & Comnetance? & $67 *$ & & \\
\hline & & & & \\
\hline & Competence4 & $.67^{*}$ & & \\
\hline \multirow{3}{*}{ Flow } & Flow2 & $.66^{*}$ & \multirow{3}{*}{.54} & \\
\hline & Flow3 & $.82 *$ & & \multirow[t]{2}{*}{.78} \\
\hline & Flow4 & $.71^{*}$ & & \\
\hline \multirow{3}{*}{ Immersion } & Immersion1 & $.82 *$ & \multirow{3}{*}{.50} & \multirow{3}{*}{.75} \\
\hline & Immersion2 & $.74 *$ & & \\
\hline & Immersion3 & $.54 *$ & & \\
\hline \multirow{5}{*}{ Enjoyment } & Enjoyment1 & $.95 *$ & \multirow{5}{*}{.81} & \multirow{5}{*}{.95} \\
\hline & Enjoyment2 & $.96 *$ & & \\
\hline & & & & \\
\hline & Enjoyment3 & $.85^{*}$ & & \\
\hline & Enjoyment4 & $.83^{*}$ & & \\
\hline \multirow{5}{*}{ Negative Affect } & Negative1 & $.56^{*}$ & \multirow{5}{*}{.51} & \multirow{5}{*}{.80} \\
\hline & Negative2 & $.63^{*}$ & & \\
\hline & Neqative? & $81 *$ & & \\
\hline & Negatıve3 & $.81^{*}$ & & \\
\hline & Negative4 & $.81^{*}$ & & \\
\hline
\end{tabular}

*Significant at the .05 probability level.

The above results show that by adapting from earlier scales developed to measure gamer experience, it is possible to develop a scale to measure gamer experience in sport video games. While many of the experiences are similar across games, six factors with a total of 21 items emerged. These six factors are Challenge, Competence, Flow, Immersion, Enjoyment and Negative Affect. This is detailed in Table 4 below. 
Table 4

Factors and Items to Measure Gamer Experience in Sport Video Games

\begin{tabular}{|c|c|}
\hline Factor & Item \\
\hline Challenge & $\begin{array}{l}\text { I felt challenged in playing the game. } \\
\text { This game requires me to perform to the best of my ability. } \\
\text { Playing this game taxes the limits of my abilities. }\end{array}$ \\
\hline Competence & $\begin{array}{l}\text { I am skillful in this game. } \\
\text { I am a success at the game. } \\
\text { I am proud of my achievements in the game. } \\
\text { At the end of the game, I felt a sense of accomplishment. }\end{array}$ \\
\hline Flow & $\begin{array}{l}\text { I felt completely absorbed in the game. } \\
\text { For a while, I forgot everything around me. } \\
\text { I lost track of time playing this game. }\end{array}$ \\
\hline Immersion & $\begin{array}{l}\text { The game feels so real. } \\
\text { I felt like I was a real F1 driver. } \\
\text { When the game ended, I had a sense of returning to the real world. }\end{array}$ \\
\hline Enjoyment & $\begin{array}{l}\text { The game was fun. } \\
\text { I enjoyed the game. } \\
\text { This is a good game. } \\
\text { Playing the game was a pleasurable experience. }\end{array}$ \\
\hline $\begin{array}{l}\text { Negative } \\
\text { Affect }\end{array}$ & $\begin{array}{l}\text { The game was frustrating. } \\
\text { I was irritated with many aspects of the game. } \\
\text { The game was boring. } \\
\text { The game was a disappointment. }\end{array}$ \\
\hline
\end{tabular}

\section{Conclusion}

In this study, six dimensions of gamer experience in sport video games have been identified. They are Challenge, Competence, Flow, Immersion, Enjoyment and Negative Affect. The two-phase analysis provides empirical evidence of the psychometric properties of the scale. Although the study tested constructive validity of the measures using two popular techniques of convergent and discriminant tests, it should be noted that the psychological 
attributes of the game experience measures could be enhanced by additional validity test. For instance, criterion validity (e.g., predictive validity, concurrent validity) could supplement the rigor of the measurement process. Such criterion validity is supported by testing the correlation between predictor variable and its criterion variable.

As noted previously, Herrewijin and Poels (2013) found support for the relationship between a player's psychological experiences and evaluation of in-game advertisements. Evidence of the relationship between a gamer's experience and the effectiveness of in-game advertising signage (e.g., brand recall and recognition) will provide validity of the current scale. In particular, by developing this scale, it will allow current studies on in-game advertisements in sport video games to go beyond identifying game characteristics in making brands more prominent within the game to enhancing gamer experience to increase the rate of brand recall. These can be examined in future studies.

However, it is also noted that there are several limitations. A sports car racing game was used in this study. While such racing games belong to the genre of sports video games, it can be arguably different from other sports video games like football, basketball and soccer. This remains a limitation of this study. Whether the dimensions of sports video games identified in a sports car racing game can be extended to other types of sports video games will need to be examined in future studies.

In addition, this model did not take into consideration the social presence or interaction with other gamers. It was noted that social presence was found to be a central component in many studies on gamer experience (Sweetser \& Wyeth, 2005; Sweetser, Johnson, \& Wyeth, 2012). Future studies will need to examine whether social presence should be included as a factor. 


\section{References}

Bagozzi, R. P., \& Yi, Y. (1988). On the evaluation of structural equation models. Journal of Academy of Marketing Science, 16(1), 74-94.

Barbara, J. (2014). Measuring User Experience in Board Games. International Journal of Gaming and Computer-Mediated Simulations, 6(1), 64-79.

Bearden, W. O., Netemeyer, R. G., \& Teel, J. E. (1989). Measurement of consumer susceptibility. Journal of Consumer Research, 15, 473-481.

Borderie, J., \& Michinov, N. (2016). Identifying Flow in Video Games: Towards a New Observation-Based Method. International Journal of Gaming and ComputerMediated Simulations, 8(3), 19-38.

Brockmyer, J. H., Fox, C. M., Curtiss, K. A., McBroom, E., Burkhart, K. M., \& Pidruzny, J. $\mathrm{N}$. (2009). The development of the game engagement questionnaire: A measure of engagement in video game-playing. Journal of Experimental Social Psychology, 45, 624-634.

Chaney, I. M., Lin, K. H., \& Chaney, J. (2004). The effect of billboards within the gaming environment. Journal of Interactive Advertising, 5(1), 37-45.

Chen, Y. F., Tsai, C. W., Liao, P. C., \& Chen, W. Y. (2012). A study on consumer intention in a web portal game from the perspective of flow experience. International Journal of Virtual Communities and Social Networking, 4(1), 1-18.

Cianfrone, B. A., Trail, G. T., Zhang, J. J., \& Lutz, R. J. (2008). Effectiveness of in-game advertisements in sport video games: an experimental inquiry on current gamers. Internation Journal of Sport Communication, 1, 195-218.

Clavio, G., Kraft, P. M., \& Pedersen, P. M. (2009). Communicating with consumers through video games: an analysis of brand development within the video gaming segment of the sports industry. International Journal of Sports Marketing \& Sponsorship.

Cowley, B., Charles, D., Black, M., \& Hickey, R. (2008). Toward an understanding of flow in video games. Computers in Entertainment (CIE), 6(2), 20.

Entertainment Software Association. (2015). Essential facts about the computer and video game industry. Washington, DC.

Fornell, C., \& Larcker, D. F. (1981). Evaluating structural equation models with unobservable variables and measurement error. Journal of Marketing Research, 18, 39-50.

Hair, J. F., Anderson, R. E., Tatham, R. L., \& Black, W. C. (1998). Multivariate data analysis (5th ed.). Upper Saddle River, NJ: Prentice-Hall Inc.

Herrewijn, L., \& Poels, K. (2013). Putting brands into play: How game difficulty and player experiences influence the effectiveness of in-game advertising. International Journal of Advertising, 32(1), 17-44.

Hrabec, O., \& Chrz, V. (2015). Flow Genres: The Varieties of Video Game Experience. International Journal of Gaming and Computer-Mediated Simulations, 7(1), 1-19.

Ijsselsteijin, W. A., de Kort, Y. A. W., \& Poels, K. (2013). The game expericne questionnaire. Eindhoven, Netherlands: Technische Universiteit Eindhoven.

Kelloway, E. K. (1998). Using LISREL for structural equation modeling: A researcher's guide. Thousand Oaks, CA: Sage Publications.

Kim, M. S., \& McClung, S. R. (2010). Acceptability and ethics of product placement in sport video games. Journal of Promotion Management, 16(4), 411-427.

Kim, Y., \& Ross, S. (2006). An exploration of motives in sport video gaming. International Journal of Sports Marketing \& Sponsorship, 8, 34-46.

Kim, Y., Walsh, P., \& Ross, S. D. (2008). An examination of the psychological and consumptive behaviors of sport video gamers. Sport Marketing Quarterly, 17(1), 4453. 
Kline, R. B. (1998). Principles and practice of structural equation modeling. New York: The Guilford Press.

Kwak, D., Clavio, G., Eagleman, A., \& Kim, K. (2010). Exploring the antecedents and consequences of personalizing sport video game experiences. Sport Marketing Quarterly, 19, 217-225.

Lang, A. (2000). The limited capacity model of mediated message processing. Journal of Communication, 50(1), 46-70.

Lee, M., \& Faber, R. J. (2007). Effects of product placement in on-line games on brand memory: A perspective of the limited-capacity model of attention. Journal of Advertising, 36(4), 75-90.

Lee, S., Seo, W. J., \& Green, B. C. (2013). Understanding why people play fantasy sport: Development of the fantasy sport motivation inventory (FanSMI). European Sport Management Quarterly, 13(2), 166-199.

Leng, H. K. (2011). A Study on the Effectiveness of In-Game Advertisements. International Journal of Sport Management, Recreation \& Tourism, 8, 65-80.

Leng, H. K., Quah, S. L., \& Zainuddin, F. (2010). The Obama Effect: An Exploratory Study on Factors Affecting Brand Recall in Online Games. International Journal of Trade, Economics and Finance, 1(1), 1-5.

Nacke, L., Drachen, A., \& Göbel, S. (2010). Methods for evaluating gameplay experience in a serious gaming context. International Journal of Computer Science in Sport, 9(2), $1-12$.

Nelson, M. R., Keum, H., \& Yaros, R. A. (2004). Advertainment or adcreep game players' attitudes toward advertising and product placement in computer games. Journal of Interactive Advertising, 5(1), 3-21.

Nichols, D., Farrand, T., Rowley, T., \& Avery, M. (2006). Brands and Gaming: The Computer Gaming Phenomenon and the Impact of Brands on Gaming: Palgrave Macmillan.

Nunnally, J. C., \& Bernstein, I. H. (1994). Psychometric theory (3rd ed.). New York: McGraw-Hill.

Poels, K., de Kort, Y., \& Ijsselsteijn, W. (2007). It is always a lot of fun!: exploring dimensions of digital game experience using focus group methodology. Paper presented at the Proceedings of the 2007 conference on Future Play.

Schneider, L. P., \& Cornwell, T. B. (2005). Cashing in on crashes via brand placement in computer games: the effects of experience and flow on memory. International Journal of Advertising, 24(3), 321-343.

Stein, A., Consalvo, M., \& Mitgutsch, K. (2012). Who are sports gamers? A large scale study of sports video game players. Convergence: The International Journal of Research into New Media Technologies.

Sweetser, P., Johnson, D. M., \& Wyeth, P. (2012). Revisiting the GameFlow model with detailed heuristics. Journal: Creative Technologies, 2012(3).

Sweetser, P., \& Wyeth, P. (2005). GameFlow: a model for evaluating player enjoyment in games. Computers in Entertainment (CIE), 3(3), 3-3.

Tabachnick, B. G., \& Fidell, L. S. (2013). Using multivariate statistics (6th ed.). Boston: Pearson.

Walsh, P., Kim, Y., \& Ross, S. D. (2008). Brand recall and recognition: a comparison of television and sport video games as presentation modes. Sport Marketing Quarterly, 17, 201-208. 